\title{
Modulation of the bronchial inflammation in sensitized guinea-pigs by FK506, nedocromil sodium and dexamethasone
}

\author{
J.R. Lapa e Silva*, C. Ruffié**, B.B. Vargaftig**, M. Pretolani**
}

Modulation of the bronchial inflammation in sensitized guinea-pigs by FK506, nedocromil sodium and dexamethasone. J.R. Lapa e Silva, C. Ruffié, B.B. Vargaftig, M. Pretolani. CERS Journals Ltd 1995.

ABSTRACT: Guinea-pigs sensitized by a subcutaneous injection of ovalbumin in $\mathrm{Al}(\mathrm{OH})_{3}$ and boosted 2 weeks later exhibit marked bronchial hyperresponsiveness to various agonists and intense bronchial wall infiltration by $\mathrm{CD}^{+} \mathrm{T}$-lymphocytes and eosinophils. We have compared the effect of FK506, a novel immunosuppressive agent, on the mucosal infiltration by $T$-cells and eosinophils with the well established drugs, nedocromil sodium and dexamethasone.

Sensitized Hartley guinea-pigs were treated subcutaneously for 5 days with FK506 $\left(100 \mu \mathrm{g} \cdot \mathrm{kg}^{-1}\right.$ daily $)$, nedocromil sodium $\left(30 \mu \mathrm{g}^{\cdot} \mathrm{kg}^{-1}\right.$ daily $)$, or dexamethasone $(200$ $\mu \mathrm{g} \cdot \mathrm{kg}^{-1}$ daily). On the day of the experiment, i.e. one week after the booster injection of antigen, the animals were killed, the lungs dissected, frozen and cryostat sections stained by immunohistochemical methods using monoclonal antibodies specific for total T-lymphocytes, $\mathrm{CD4}^{+}$and $\mathrm{CD8}^{+}{ }^{-} \mathrm{T}$-cells. Cyanide-resistant eosinophil peroxidase activity was used to stain the eosinophils. Sections were coded and positive cells enumerated in the lamina propria and adventitia of the bronchi.

Sensitized and antigen-stimulated vehicle-treated guinea-pigs showed marked infiltration of the bronchial wall by $\mathrm{CD4}^{+} \mathrm{T}$-lymphocytes and eosinophils compared with sensitized, non-antigen stimulated animals. As compared to vehicle, FK506 or dexamethasone abolished the T-cell/eosinophil invasion in the bronchial wall, whereas nedocromil sodium was ineffective in protecting the lungs from $T$ lymphocyte or eosinophil infiltration.

We conclude that both FK506 and dexamethasone are effective in curtailing bronchial inflammation in allergic guinea-pigs, whereas nedocromil sodium did not resolve the inflammation associated with T-lymphocytes or eosinophils.

Eur Respir J., 1995, 8, 1321-1327.
*Hospital Universitário Clementino Fraga Filho, Universidade Federal do Rio de Janeiro, Brazil. **Unité de Pharmacologie Cellulaire, Unité Associée Institut Pasteur/INSERM no. 285, Paris, France.

Correspondence: M. Pretolani Unité de Pharmacologie Cellulaire

Unité Associée Institut Pasteur/INSERM no. 285

25 rue du Dr. Roux

75015 Paris

France

Keywords: Eosinophils glucocorticosteroids immunohistochemistry immunosuppressive drugs T-lymphocytes

Received: October 251994

Accepted after revision March 231995
Bronchial mucosal inflammation is recognized as one of the main events associated with bronchial hyperresponsiveness and asthma [1]. Many cells and their secreted products participate in the pathogenesis of the disease [2], but it is now well-established that co-operation between eosinophils and T-lymphocytes is necessary for its development [3]. We have employed animal models to investigate the relationship between both cell types in the pathogenesis of bronchial inflammation and hyperresponsiveness. In particular, we demonstrated that isolated lungs from guinea-pigs sensitized with subcutaneous (s.c.) injections of ovalbumin at days 0 and 14, and killed on day 21 exhibit marked bronchopulmonary responsiveness to various agonists [4], as well as a marked infiltration of the bronchial wall by $\mathrm{CD} 4^{+} \mathrm{T}-$ lymphocytes and eosinophils [5]. Furthermore, when challenged with antigen on day 21 , other signs of intense bronchial inflammation, such as marked bronchial epithelial shedding, were found in sensitized and antigen-stimulated animals but not in sensitized, non- antigen-stimulated guinea-pigs, where $\mathrm{CD}^{+}{ }^{+} \mathrm{T}$-lymphocytes had not been increased [5].

A drug recently introduced in asthma therapy is nedocromil sodium. In our experimental setting, nedocromil sodium demonstrated anti-inflammatory properties. Indeed, using the presently described model of ovalbuminsensitized guinea-pigs we found that a 1 week treatment with nedocromil sodium markedly reduced the proportion of eosinophils in the bronchoalveolar fluid (BALF) of sensitized and antigen-stimulated animals, a phenomenon accompanied by a reduction in bronchopulmonary hyperresponsiveness [6].

FK506 is a newly developed immunosuppressant that has been extensively investigated, not only for its ability to reduce rejection of allograft transplants, but also for its anti-inflammatory activities in immunological conditions [7].

In the present study, using ovalbumin-sensitized and antigen-stimulated guinea-pigs, we investigated the modulatory activity of FK506 on allergic bronchial inflammation 
and compared it with the effects of the well-established drugs, nedocromil sodium and dexamethasone.

\section{Materials and methods}

\section{Animals and sensitization procedure}

Male Hartley guinea-pigs (Charles Rivers, St. Aubin les Elbeuf, France) weighing 400-600 g were actively sensitized on day 0 by a s.c. injection of $0.5 \mathrm{ml}$ of $0.9 \%$ $\mathrm{NaCl}$ (saline, Merck, Darmstadt, Germany), containing $10 \mu \mathrm{g}$ of ovalbumin (Miles, Naperville, IL, USA) dispersed in $1 \mathrm{mg} \mathrm{Al}(\mathrm{OH})_{3}$ (Merck). On day 14, the animals were either administered a booster injection under the same conditions, or received the adjuvant only. All animals were killed on day 21 .

This immunization procedure promotes the production of high titres of specific homocytotropic immunoglobulin $\mathrm{G}(\mathrm{IgG})$ antibodies, as evaluated by passive cutaneous anaphylaxis [4].

\section{Drug treatments}

Two experimental procedures were used, firstly to investigate the effects of FK506 and secondly to examine the anti-inflammatory properties of dexamethasone and nedocromil sodium. In preliminary experiments, sensitized guinea-pigs were treated s.c. with either $1 \mathrm{mg}$ or $100 \mu \mathrm{g} \cdot \mathrm{kg}^{-1}$ daily FK506 for 5 days. As both of these FK506 dosages are effective in inhibiting the effects resulting from the booster injection, such as inhibition of T-lymphocyte and eosinophil infiltration in the bronchial mucosa, the lower dose regimen was employed in this study (data not shown). The drug was prepared according to instructions of the manufacturer: $10 \mathrm{mg}$ FK506 were dissolved in $1 \mathrm{~mL}$ ethanol (Merck, Darmstadt, Germany) and $0.5 \mathrm{~mL}$ of this solution was mixed with $0.1 \mathrm{~mL}$ Tween 80 (Fluka Chemika, Buchs, Switzerland). The whole mixture was diluted with $4.4 \mathrm{~mL}$ of sterile saline to give a final concentration of $1 \mathrm{mg} \cdot \mathrm{mL}^{-1} \mathrm{FK} 506$. Dilutions were performed in saline. Control animals received similar amounts of vehicle only, i.e. ethanol/Tween 80 injected by s.c. route.

For nedocromil sodium treatment, guinea-pigs received $30 \mathrm{mg} \cdot \mathrm{kg}^{-1}$ daily of the drug, injected s.c. for 5 days, and control animals received similar amounts of sterile saline. This dose and administration regimen for nedocromil sodium was selected on the basis of a previously reported study, using the same sensitization procedure [6].

Finally, a group of sensitized guinea-pigs were treated s.c. with $20 \mathrm{mg} \cdot \mathrm{kg}^{-1}$ daily dexamethasone phosphate (Sigma Chemical Co., St. Louis, MO, USA) for 5 days and the controls received similar amounts of sterile saline.

\section{Handling of samples}

The animals were terminally anaesthetized with 60 $\mathrm{mg} \cdot \mathrm{kg}$ sodium pentobarbital, (Clin-Midy, Montpellier,
France) injected intraperitoneally, exsanguinated via the abdominal aorta, and the contents of the thoracic cavity resected "en bloc". The lungs were inflated via the trachea with $3 \mathrm{~mL}$ of Histocon ${ }^{\circledR}$ ) (Polysciences, Warrington, PA, USA), the lobes dissected and mounted in optimum cutting temperature compound (BDH, Poole, UK), and snap-frozen in isopentane (Prolabo, Paris, France) cooled by liquid nitrogen. The frozen blocks were stored at $80^{\circ} \mathrm{C}$ prior to use. Cryostat sections were collected on glass slides coated with poly-L-lysine (Sigma), fixed in chloroform-acetone (Merck) vol/vol for $10 \mathrm{~min}$, and stored at $-20^{\circ} \mathrm{C}$ prior to use.

\section{Immunohistochemistry}

Consecutive sections of each lobe were stained with the following monoclonal antibodies: H159 for mature T-lymphocytes, staining between $70-90 \%$ of mature Tcells [8]; H155 recognizing CD4+ T-cells [9]; CT6 for $\mathrm{CD}^{+}$T-cells [10]. For the mouse antibody (CT6), alkaline phosphatase anti-alkaline phosphatase (APAAP) staining procedure was performed as described previously [5], using rabbit immunoglobulin (Ig) to mouse Ig (Z259, Dakopatts a/s, Copenhagen, Denmark) and mouse APAAP (D651, Dakopatts a/s), followed by incubation with the substrate Fast Red TR (Sigma) and naphthol AS MX phosphate (Sigma), and light haematoxylin counterstaining. For the rat monoclonal antibodies (H159 and H155), APAAP was also performed, using rabbit Ig to rat Ig (Z455, Dakopatts a/s) and rat APAAP (D488, Dakopatts a/s), followed by similar development. A histochemical method for cyanide-resistant eosinophil peroxidase (EPO) activity, employing diaminobenzidine (Merck), $\mathrm{H}_{2} \mathrm{O}_{2}$ and potassium cyanide (Merck) was used to stain eosinophils [11].

\section{Quantitation and statistics}

At least two sections were stained with each antibody or the EPO technique, coded and read in a "blind" fashion. The positive cells were enumerated in two histological compartments of the bronchial wall, the bronchial lamina propria, between the basal lamina and the smooth muscle, and in the adventitia, between the smooth muscle and the cartilage. Cells were not quantitated in the epithelial compartment due to frequent shedding of the epithelium. The area of each compartment was calculated by using an eyepiece graticule of known area. This area and the number of positive cells were determined on each microscopic field, and at least 10 high power fields were analysed per compartment. The results for each slide were presented as the number of positive cells per unit area $\left(6.25 \times 10^{4} \mu \mathrm{m}^{2}\right.$, the total area of the graticule). The results were presented as mean \pm SEM and the groups compared by one-way analysis of variance, followed by the multiple range test of Student-NewmanKeuls, using the statistical software SPSS. Differences between groups were considered statistically significant when $\mathrm{p}$ was equal or less than 0.05 . 
a)

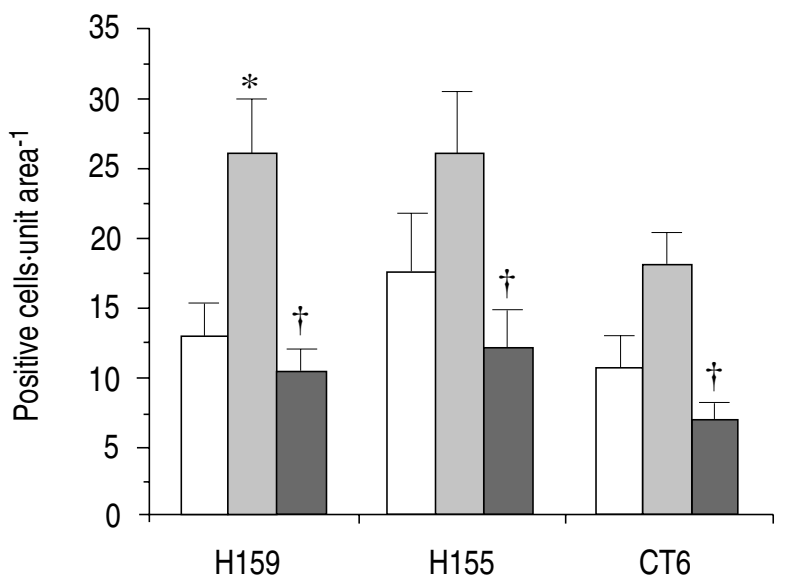

b)

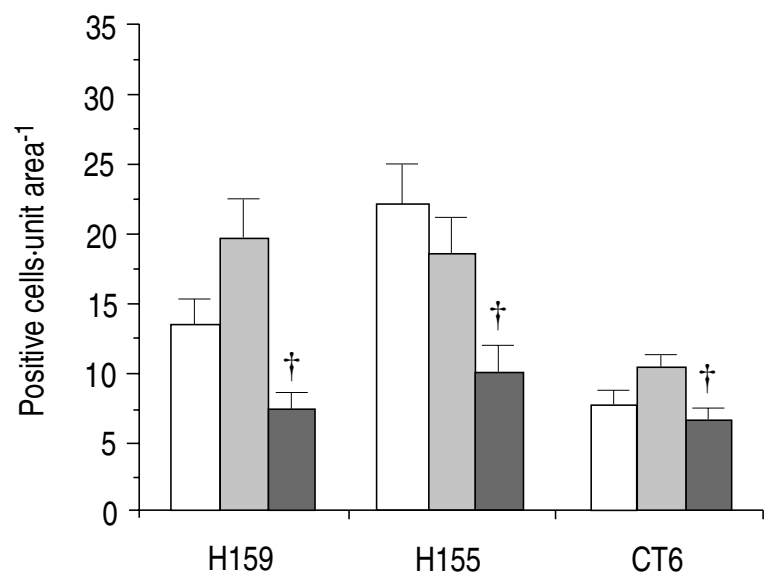

Fig. 1. - Distribution of T-lymphocytes and subsets in the bronchial wall compartments a) lamina propria and b) adventitia from: sensitized non-antigen-stimulated vehicle-injected guinea-pigs ( $\square$ ); sensitized and antigen-stimulated vehicle-injected guinea-pigs ( $\square$ ); or FK506 (100 $\mu$ g.kg-1 daily for 5 days s.c.)-injected guinea-pigs $(\square)$. Results represent the number of positive cells per unit area of bronchial compartment $\left(6.25 \times 10^{4}\right.$ $\mu^{2}$ ). Data are mean \pm SEM of 5-15 experiments. H159: monoclonal antibody for mature T-cells; H155: monoclonal antibody for CD4+ T-cells; CT6: monoclonal antibody for $\mathrm{CD}^{+} \mathrm{T}$-cells. $*: \mathrm{p}<0.05$, as compared to non-antigen-stimulated vehicle-treated animals; $\dagger: \mathrm{p}<0.05$, as compared to antigen-stimulated vehicle-injected animals.

\section{Results}

\section{Effects of FK506 on cellular infiltration in the bronchial mucosa}

The effects of the FK506 or its vehicle on T-lymphocytes, T-cell subsets and eosinophils were analyzed in the bronchial lamina propria and adventitia of sensitized guinea-pigs. The booster injection of antigen to sensitized guinea-pigs was followed by a marked T-lymphocyte and eosinophil infiltration in the bronchial mucosa. T-cell influx was due mostly to $\mathrm{CD}^{+}{ }^{+} \mathrm{T}$-lymphocyte recruitment (fig. 1). Increase in the number of $\mathrm{CD}^{+}$ T-lymphocytes in the bronchial lamina propria was not detected (fig. 1). Cellular infiltration was more intense in the lamina propria than in the adventitia (figs. 1 and 2). Treatment of the sensitized animals with $100 \mu \mathrm{g} \cdot \mathrm{kg}^{-1}$ daily FK506 for 5 days resulted in suppression of T-lymphocyte and subset recruitment in both bronchial compartments examined (fig. 1). It is noteworthy that FK506 reduced cell counts, including $\mathrm{CD}^{+} \mathrm{T}-$-cells, below the basal values observed in control unboosted animals (fig. 1).

Sensitized and antigen stimulated, vehicle-treated guineapigs failed to show a significant increment in the numbers of $\mathrm{EPO}^{+}$cells in the bronchial mucosa, compared with non-antigen-stimulated animals (fig. 2). However, a marked and significant reduction in the number of positive cells was noted in the bronchial lamina propria of animals treated with FK506, compared with antigenstimulated vehicle-treated guinea-pigs. Indeed, $\mathrm{EPO}^{+}$cell counts were lower than those found in the bronchial tissue from non-antigen stimulated vehicle-injected guinea-pigs (fig. 2).

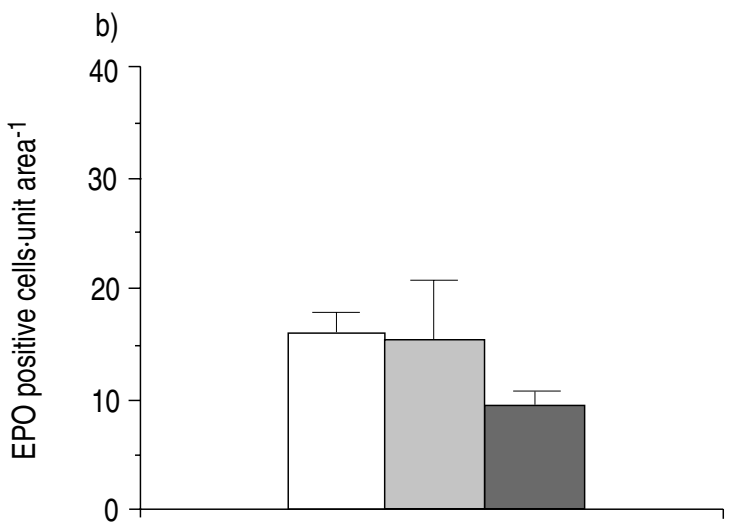

Fig. 2. - Distribution of eosinophil peroxidase (EPO)+ cells in the bronchial wall compartments a) lamina propria and b) adventitia from: sensitized non-antigen-stimulated vehicle-injected guinea-pigs ( $\square$ ); sensitized and antigen-stimulated vehicle-injected guinea-pigs ( $\square$ ); or FK506 (100 $\mu \mathrm{g} \cdot \mathrm{kg}^{-1}$ daily for 5 days s.c.)-injected guinea-pigs $(\square)$. Results represent the number of positive cells per unit area of bronchial compartment $\left(6.25 \times 10^{4} \mu \mathrm{m}^{2}\right)$. Data are mean \pm SEM of $5-15$ experiments. $*$ : $\mathrm{p}<0.05$, as compared to non-antigen-stimulated vehicle-treated animals; $\dagger: \mathrm{p}<0.05$, as compared to antigen-stimulated vehicle-injected animals. 
a)

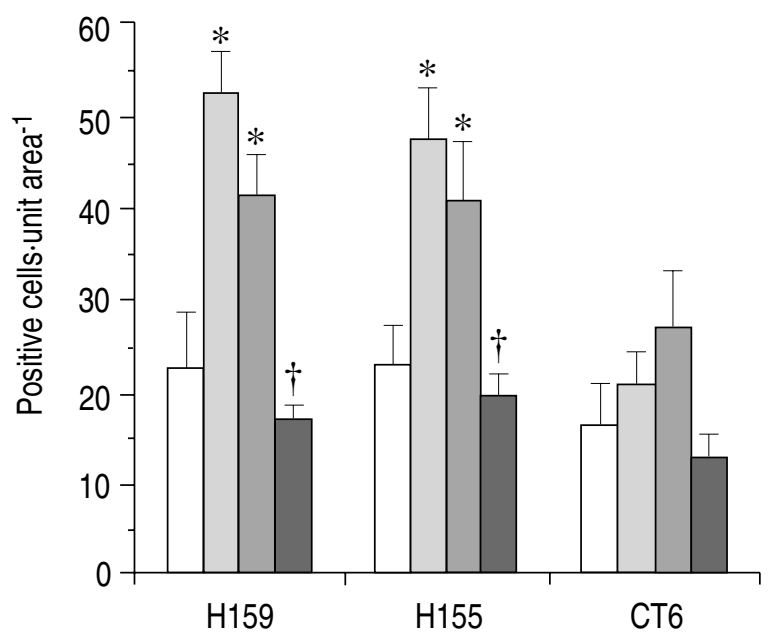

b)

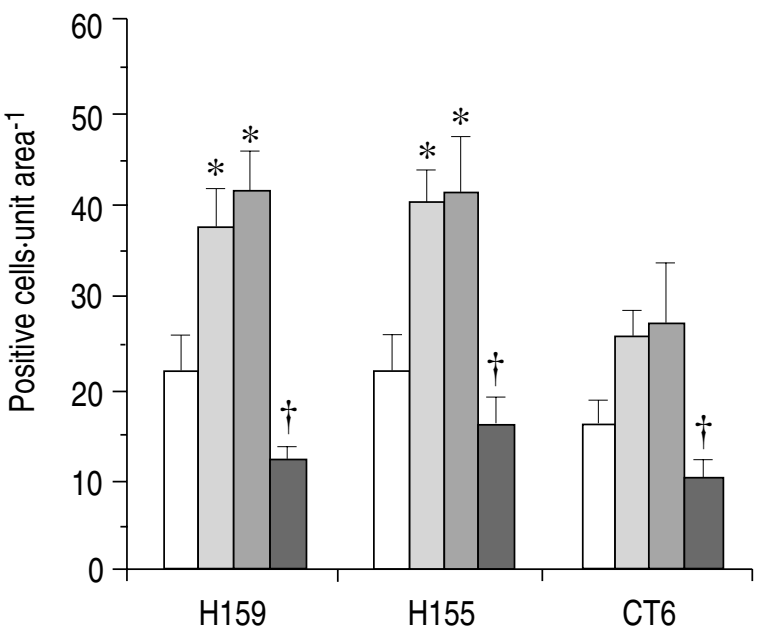

Fig. 3. - Distribution of T-lymphocytes and subsets in the bronchial wall compartments a) lamina propria and b) adventitia from: sensitized nonantigen-stimulated vehicle-injected guinea-pigs $(\square)$; sensitized and antigen-stimulated vehicle-injected guinea-pigs ( $\square$ ); nedocromil sodium (30 $\mathrm{mg} \cdot \mathrm{kg}^{-1}$ daily for 5 days s.c.) injected guinea-pigs ( $\square$ ); or dexamethasone $\left(20 \mathrm{mg} \cdot \mathrm{kg}^{-1}\right.$ daily for 5 days s.c.)-injected guinea-pigs ( $\square$ ). Results represent the number of positive cells per unit area of bronchial compartment $\left(6.25 \times 10^{4} \mathrm{um}^{2}\right)$. Data are mean \pm SEM of 6-12 experiments. H159: monoclonal antibody for mature T-cells; H155: monoclonal antibody for CD4+ T-cells; CT6: monoclonal antibody for CD8 ${ }^{+}$T-cells. * : p<0.05, as compared to non-antigen-stimulated vehicle-tested animals; $\uparrow: \mathrm{p}<0.05$, as compared to antigen stimulated vehicle-injected animals.

\section{Effects of nedocromil sodium and dexamethasone on cellular infiltration in the bronchial mucosa}

The effects of nedocromil sodium and of the glucocorticosteroid dexamethasone or their vehicle, saline, on T-lymphocytes, T-cell subsets and eosinophils were analysed in the bronchial wall compartments of sensitized and antigen-stimulated guinea-pigs (figs. 3 and 4). No differences were observed in the total T-lymphocyte or $\mathrm{CD}^{+}$and $\mathrm{CD}^{+}{ }^{+} \mathrm{T}$-cell numbers when nedocromil sodium (30 $\mathrm{mg} \cdot \mathrm{kg}^{-1}$ daily for 5 days) and saline-treated control animals were compared (fig. 3). However, dexamethasone $\left(20 \mathrm{mg} \cdot \mathrm{kg}^{-1}\right.$ daily for 5 days $)$ suppressed

a)

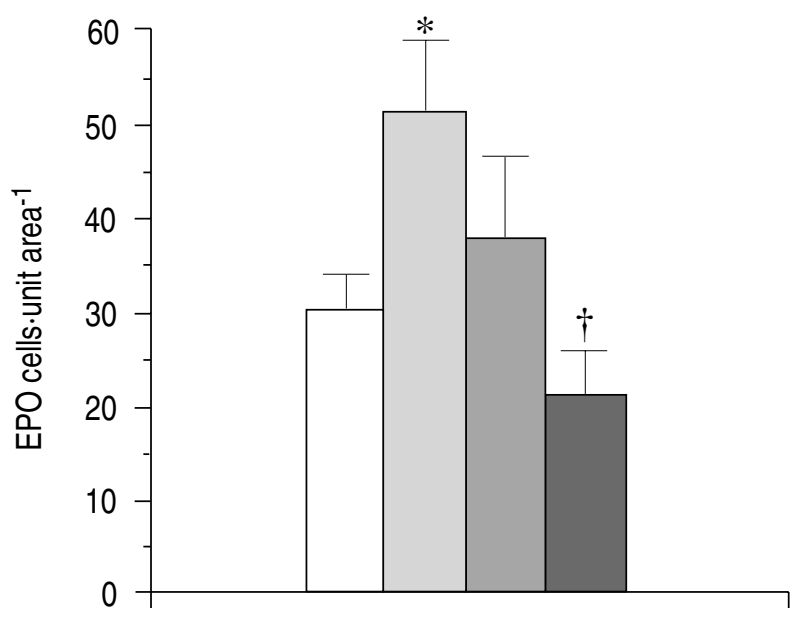

total T-cell and CD4+ T-lymphocyte recruitment both in the bronchial lamina propria and the adventitia (fig. 3). The number of $\mathrm{CD}^{+} \mathrm{T}$-lymphocytes did not vary significantly in the different groups (fig. 3).

Figure 4 shows the results for $\mathrm{EPO}^{+}$cells, i.e. eosinophils, in the mucosal compartments. Again, dexamethasone markedly reduced the number of eosinophils infiltrating the bronchial lamina propria $(\mathrm{p}<0.05)$. Reduction in eosinophils in the mucosa was not found in animals treated with nedocromil sodium.

Figures 5 and 6 illustrate the effects of the different anti-inflammatory drugs described above on antigen-induced cellular recruitment in the bronchial lamina propria.

b)

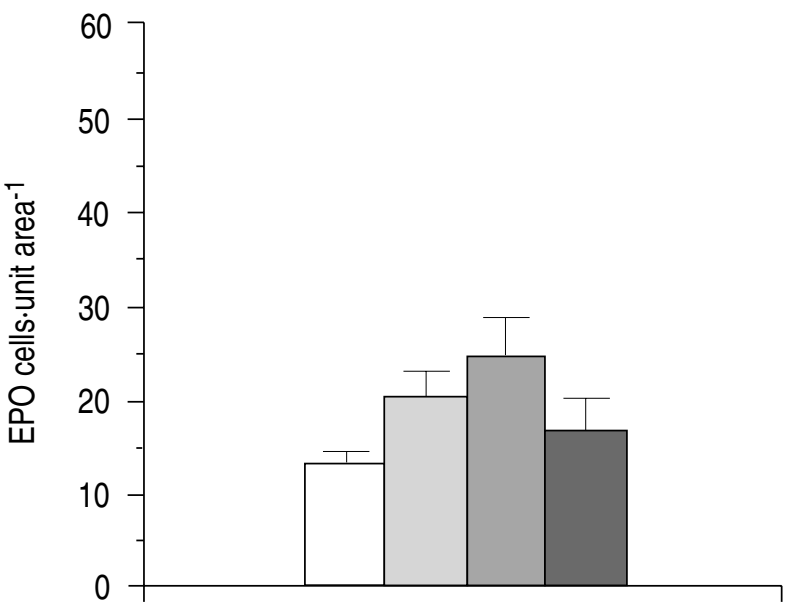

Fig. 4. - Distribution of eosinophil peroxidase (EPO) ${ }^{+}$cells in the bronchial wall compartments a) lamina propria and b) adventitia from: sensitized non-antigen-stimulated vehicle-injected guinea-pigs $(\square)$; sensitized and antigen-stimulated vehicle-injected guinea-pigs $(\square)$; nedocromil sodium (30 mg. $\mathrm{kg}^{-1}$ daily for 5 days s.c.) injected guinea-pigs ( $\square$ ); or dexamethasone ( $20 \mathrm{mg} \cdot \mathrm{kg}^{-1}$ daily for 5 days s.c.)-injected guinea-pigs

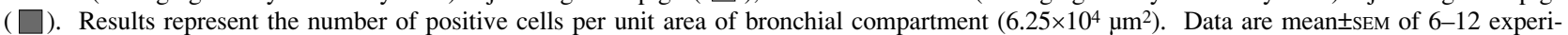
ments. *: $\mathrm{p}<0.05$, as compared to non-antigen-stimulated vehicle-tested animals; $\dagger: \mathrm{p}<0.05$, as compared to antigen stimulated vehicle-injected animals. 

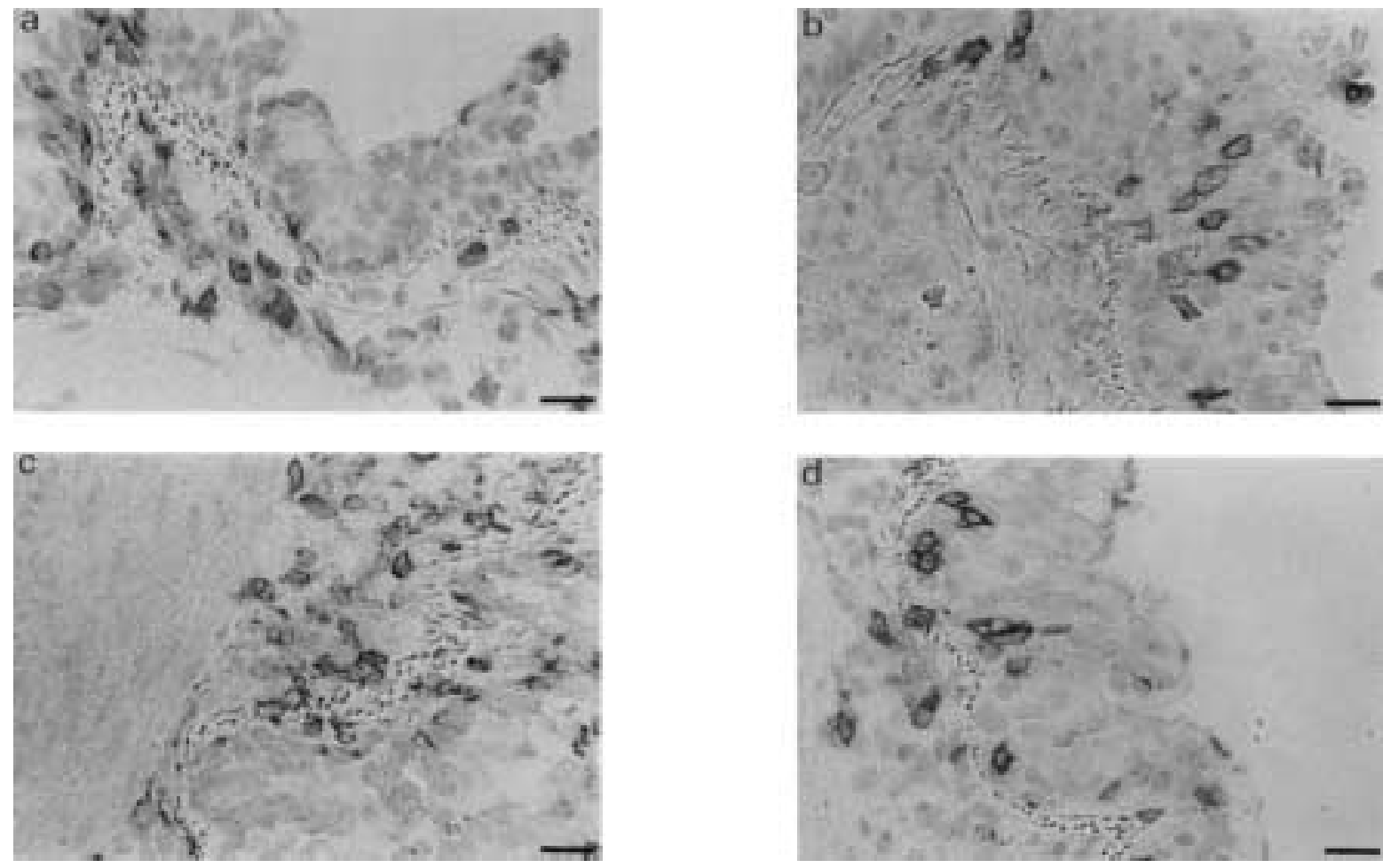

Fig. 5. - Identification of T-lymphocytes (H159, alkaline phosphatase anti-alkaline phosphatase (APAAP)) in the bronchial lamina propria of sensitized non-antigen-stimulated or antigen-stimulated guinea-pigs. a) antigen-stimulated vehicle treated animal, showing intense T-lymphocyte infiltration; b) antigen-stimulated FK506-treated guinea-pig, with scant positive cells in the bronchial mucosa; c) antigen-stimulated nedocromil sodium-treated animal with many positive cells; d) dexamethasone-treated guinea-pig, again showing few positive cells in the bronchial submucosa. (Original magnification $\times 400$; internal scale bar $=20 \mu \mathrm{m})$.
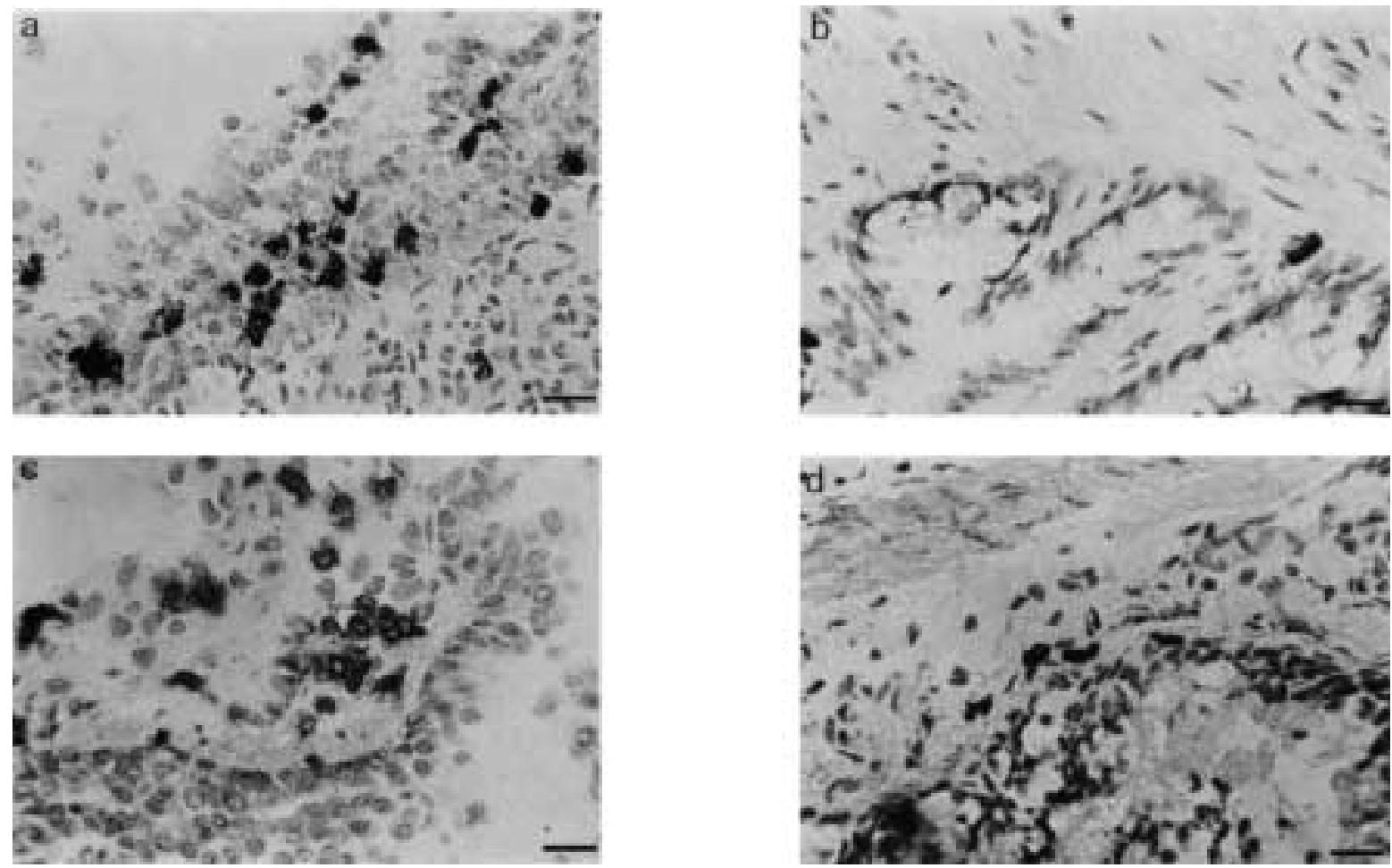

Fig. 6. - Lung sections from sensitized and antigen-stimulated guinea-pigs, stained for cyanide-resistant eosinophil peroxidase (EPO) activity. a) antigen-stimulated saline-treated animal. with numerous positive cells; b) antigen-stimulated FK506-treated guinea-pig, showing scant $\mathrm{EPO}^{+}$cells in the bronchial mucosa; c) antigen-stimulated nedocromil sodium treated guinea-pig, with intense $\mathrm{EPO}^{+}$cells infiltrating the bronchial mucosa; d) antigen-stimulated dexamethasone-treated animal, again showing few positive cells. (Original magnification $\times 400$; internal scale bar $=20 \mu \mathrm{m}$ ). 


\section{Discussion}

The present study demonstrates that FK506 has a profound effect on cellular infiltration into the bronchial compartments of sensitized guinea-pigs, and can completely curtail the inflammatory consequences of the booster injection of antigen. Even $\mathrm{CD}^{+} \mathrm{T}$-cells, although not substantially raised in the boosted animal, were reduced to levels below those of non-antigen-stimulated animals. The $\mathrm{CD} 8^{+} \mathrm{T}$-cell subset apparently plays a minor role in the allergic inflammation in this model. Both the present study and the results previously published [5] have consistently demonstrated that T-lymphocyte infiltration in the airways of sensitized and boosted guineapigs is due solely to $\mathrm{CD}^{+}{ }^{+} \mathrm{T}$-cells. Although $\mathrm{CD}^{+}$ T-cells did not increase in boosted animals as compared with their non-boosted counterparts, the fact that FK506 treatment reduced their levels below the numbers seen in non-boosted, vehicle-treated animals suggests a possible role for this subset in the allergic inflammation. However, it was beyond the aim of the present study to investigate the possible functional role of $\mathrm{CD}^{+}$cells in the inflammation. Similarly, dexamethasone was able to abolish the inflammatory stimulus caused by the antigen stimulation in sensitized animals, demonstrated by a reduction in total $\mathrm{T}$-cells, $\mathrm{CD}^{+}{ }^{+} \mathrm{T}$-lymphocyte and eosinophil numbers to prebooster levels. $\mathrm{CD}^{+} \mathrm{T}$-cell numbers were also reduced in the bronchial adventitia, although not to the same level as after treatment with FK506. In contrast, nedocromil sodium was unable to interfere with the infiltration of the bronchial wall by total T-cells, CD4+ T-lymphocytes, or eosinophils.

FK506 is a fungus-derived macrolide with intense immunosuppressive activity because of the inhibition of signal transduction pathways leading to T-cell activation [7]. FK506 prevents interleukin-2 (IL-2) production similarly to, but more effectively than, cyclosporin [12]. Many reports from the literature indicate that FK506 also inhibits the production of various cytokines [13, 14], and acts on mast cell function [15]. Hom and EstRIDGE [16] also demonstrated that FK506 inhibits the production of granulocyte/macrophage colony-stimulating factor (GMCSF) and interleukin-3 (IL-3) by human peripheral blood eosinophils upon stimulation with the calcium ionophore A23187. In contrast, FK506 had minimal effect on the interleukin-5 (IL-5)-mediated survival of eosinophils [16], suggesting that this drug interferes with the capacity of eosinophils to engage in events leading to chronic inflammation. Together, these findings encourage the use of FK506 in experimental conditions involving allergic inflammation and bronchial hyperresponsiveness. FUKUDA et al., [17] have shown that FK506, when given to sensitized and challenged guinea-pigs from the beginning of the immunization period, was able to inhibit both bronchial hyperreactivity to acetylcholine and eosinophil infiltration into the tracheal wall. In a subsequent study, the authors used inhaled FK506 in sensitized guinea-pigs and found a striking reduction in eosinophil accumulation in the trachea, as well as in bronchial responsiveness to acetylcholine [18].

The clinical basis for the use of immunosuppressants in chronic asthma is glucocorticosteroid resistance, which is presented by a limited number of patients. In these circumstances, immunosuppressants, such as methotrexate, gold and cyclosporin A, have proved efficacious in controlling persistent symptoms [19]. AleXANDER et al., [20] performed a double-blind, cross-over study with cyclosporin A in patients with severe asthma and corticosteroid resistance and found amelioration, not only in clinical indices but also in functional parameters.

In the present study, we compared the effect of FK506 with that of well-established drugs. Dexamethasone showed an effect on the cellular parameters analysed similar to that of FK506. Nedocromil sodium failed to protect sensitized and antigen stimulated guinea-pigs from T-cell, CD4 ${ }^{+}$T-lymphocyte or eosinophils recruitment. However, in a previous study, we demonstrated that nedocromil sodium, administered to sensitized guineapigs for 1 week after the booster injection of antigen, substantially reduced the enhanced platelet-activating factor (PAF)-induced bronchoconstriction and mediator release from isolated lungs, and inhibited hypereosinophilia in the bronchoalveolar compartment [6]. Many other reports have confirmed these findings in experimental models, showing marked effects of nedocromil sodium on airway responsiveness and eosinophilia, either bronchial or parenchymal [21, 22]. These experimental findings were corroborated by clinical studies, where the efficacy of nedocromil sodium in reducing symptoms and improving functional parameters was also seen [23]. However, none of these studies addressed the possible effects of nedocromil sodium on the T-lymphocyte infiltration in the bronchial mucosa, either in experimental models or clinical studies. In an in vitro study, O'HEHIR and MoQbel [24] investigated the action of nedocromil sodium on specific allergen- or IL-2-induced proliferation of a human $\mathrm{CD}^{+}{ }^{+}$house dust mite-specific T-cell clone isolated from a patient with perennial rhinitis. No inhibitory effect was observed on proliferation indices in cultures treated with nedocromil sodium, but dexamethasone, in similar conditions, was able to inhibit the T-cell proliferation. The authors suggested that suppression of the late phase asthmatic response by nedocromil sodium may be due to mechanisms other than its action on $\mathrm{CD} 4^{+} \mathrm{T}$-lymphocytes.

There is circumstantial evidence that the association between activated T-lymphocytes, mainly of $\mathrm{CD}^{+}{ }^{+}$subset, and eosinophils play a major role in the development of the bronchial inflammation that accompanies bronchial hyperresponsiveness [3]. The presence of large numbers of T-cells, also of $\mathrm{CD}^{+}{ }^{+}$phenotype, and eosinophils were also reported in experimental models. These CD4 ${ }^{+}$T-cells belong preferentially to the Th2 subset, secreting cytokines, such as IL-5, known to influence many aspects of the eosinophil biology. Neutralizing antibodies against IL-5 prevented eosinophil infiltration in the bronchial mucosa of allergic animals, and also blocked antigen-induced bronchial hyperresponsiveness [25]. FK506 and dexamethasone may, thus, prevent allergic airway inflammation not only via the reduction in the numbers of $\mathrm{CD}^{+}{ }^{+} \mathrm{T}$-lymphocytes, but also possibly by blocking the production of relevant cytokines. 
In conclusion, FK506 and dexamethasone were able to prevent the cellular response seen in the bronchial wall of sensitized and antigen stimulated guinea-pigs. Nedocromil sodium, however, did not interfere with mucosal eosinophilia and was unable to change the T-lymphocyte component of the allergic inflammation in this experimental model.

Acknowledgements: The authors are grateful to K. Murato (Fujisawa GmbH, Munich, Germany) for the gift of FK506, A. Norris (Fisons plc., Loughborough, UK) for the gift of nedocromil sodium, H. Schäffer and R. Burger (Robert-Koch Institute, Berlin, Germany) for providing the monoclonal antibodies H155 and H159, R. Scheper (Free University, Amsterdam, The Netherlands) for the gift of CT6, D. Baker (Royal College of Surgeons of England, London, UK) for helpful advice on the immunohistochemical techniques, and J. Lefort, for expert technical help. J.R. Lapa e Silva was partially funded by CEPG/UFRJ, FUJB, and CNPq.

\section{References}

1. National Heart, Lung and Blood Institute. International consensus report on diagnosis and treatment of asthma. Eur Respir J 1992; 5: 601-641.

2. Kay AB. Asthma and inflammation. J Allergy Clin Immunol 1991; 87: 893-910.

3. Corrigan CJ, Kay AB. T-cells and eosinophils in the pathogenesis of asthma. Immunol Today 1992; 13: 501-506.

4. Pretolani M, Lefort J, Vargaftig BB. Active immunization induces lung hyperresponsiveness in the guineapig: pharmacological modulation and triggering role of the booster injection. Am Rev Respir Dis 1988; 138: 1572-1578.

5. Lapa e Silva JR, Bachelet CM, Pretolani M, Baker D, Scheper RJ, Vargaftig BB. Immunopathological alterations in the bronchi of immunized guinea-pigs. Am J Respir Cell Mol Biol 1993; 9: 44-53.

6. Pretolani M, Lefort J, Silva P, et al. Protection by nedocromil sodium of active immunization-induced bronchopulmonary alterations in the guinea-pig. Am Rev Respir Dis 1990; 141: 1259-1265.

7. Blackham A, Griffiths RJ. The effect of FK506 and cyclosporin A on antigen-induced arthritis. Clin Exp Immunol 1991; 86: 224-228.

8. Schäffer H, Burger R. Analysis of mature guinea-pig Tcells with a monoclonal antibody directed against a framework determinant of the T-cell receptor for antigen. Scand J Immunol 1992; 36: 587-595.

9. Schäffer H, Burger R. Identification and functional characterization of guinea-pig CD4: antibody binding transduces a negative signal on T-cell activation. Immunology 1991; 72: 261-268.

10. Tan BTG, Ekellar F, Luirink J, Rimmelzaan G, de Jonge AJR, Scheper RJ. Production of monoclonal antibodies defining guinea-pig T-cell surface markers and a strain 13 Ia-like antigen: the value of immunohistological screening. Hybridoma 1985; 4: 115-124.
11. Zucker-Franklin D, Grusky G. The identification of eosinophil colonies in soft-agar cultures by differential staining for peroxidase. J Histochem Cytochem 1976; 24: $1270-1272$.

12. Bishop DK, Li W. Cyclosporin A and FK506 mediated differential effects on T-cell activation in vivo. $J$ Immunol 1992; 148: 1049-1054.

13. Andersson J, Nagy S, Grith CG, Andersson V. Effects of FK506 and cyclosporin A on cytokine production studied in vitro at a single-cell level. Immunology 1992; 75: 136-142.

14. Goldfeld AE, Flemington EK, Boussiotis VA, et al. Transcription of the tumour necrosis factor alpha gene is rapidly induced by anti-immunoglobulin and blocked by cyclosporin A and FK506 in human B-cells. Proc Natl Acad Sci USA 1992; 89: 12198-12201.

15. Hatfield SM, Mynderse JS, Roehm NN. Rapamycin and FK506 differentially inhibit mast cell cytokine production and cytokine-induced proliferation and act as reciprocal antagonists. J Pharmacol Exp Ther 1992; 261: 970-976.

16. Hom JT, Estridge T. FK506 and rapamycin modulate the functional activities of human peripheral blood eosinophils. Clin Immunol Immunopathol 1993; 68: 293-300.

17. Fukuda J, Akutsu I, Nakajima K, et al. The role of eosinophils, neutrophils and lymphocytes for the development of bronchial hyperresponsiveness in a guinea-pig model of asthma. Jpn J Thorac Dis 1990; 28: 12881293.

18. Akutsu I, Fukuda T, Majima K, Makino S. Inhibitory effect of inhaled FK506 on increased bronchial responsiveness and eosinophil infiltration in the airway mucosa. Arerugi 1992; 41: 543-547.

19. Calderón E, Lockey RF, Bukantz SG, Coffey RG, Ledford DK. Is there a role for cyclosporin in asthma? $J$ Allergy Clin Immunol 1992; 89: 629-636.

20. Alexander N, Barnes N, Kay AB. Cyclosporin in asthma. Lancet 1992; 339: 324-328.

21. Schellenberg RR, Ishida K, Thomson RJ. Nedocromil sodium inhibits airway hyperresponsiveness and eosinophilic infiltration induced by repeated antigen challenge in guinea-pigs. Br J Pharmacol 1991; 103: 18421846.

22. Hutson PA, Holgate ST, Church MK. Inhibition of nedocromil sodium of early and late phase bronchoconstriction and airway cellular infiltration provoked by ovalbumin inhalation in conscious sensitized guinea-pigs. $\mathrm{Br}$ J Pharmacol 1988; 94: 6-8.

23. Aalbers R, Kaunfmann HF, Groen H, Koèter GK, de Monchy JGR. The effects of nedocromil sodium on the early and late reaction and allergen-induced bronchial hyperresponsiveness. J Allergy Clin Immunol 1991; 87: 993-1001.

24. O'Hehir RE, Moqbel R. Action of nedocromil sodium and sodium cromoglycate on cloned human allergenspecific CD4+ T-lymphocytes. Drugs 1989; 37 (Suppl. 1): $23-25$.

25. Ooosterhout AJMV, Ladenius ARC, Savelkoul HFJ, Ark IV, Delsman KC, Nijkamp FJ. Effect of anti-IL-5 and IL-5 on airway hyperreactivity and eosinophils in guineapigs. Am Rev Respir Dis 1993; 147: 548-552. 